\title{
Evaluation of Stochastic Global Optimization Methods in the Design of Complex Distillation Configurations
}

\author{
Julián Cabrera-Ruiz ${ }^{1}$, Erick Yair Miranda-Galindoํㅜ, Juan Gabriel \\ Segovia-Hernández ${ }^{1}$, Salvador Hernández ${ }^{1}$ and Adrián Bonilla-Petriciolet ${ }^{2}$ \\ ${ }^{1}$ Universidad de Guanajuato, Chemical Engineering Department, Campus Guanajuato, \\ C.P. 36050, Guanajuato, \\ 2Instituto Tecnológico de Aguascalientes, Chemical Engineering Department, C.P. 20256, \\ Aguascalientes, \\ México
}

\section{Introduction}

Distillation is a widely used separation process and is a very large consumer of energy. In process design, a significant amount of research work has been done to improve the energy efficiency of distillation systems in terms of either the design of optimal distillation schemes or for improving internal column efficiency. Still, the optimal design of multicomponent distillation systems remains one of the most challenging problems in process engineering (Kim \& Wankat, 2004). The economic importance of distillation separations has been a driving force for the research in synthesis procedures for more than 30 years. For the separation of an $\mathrm{N}$-component mixture into $\mathrm{N}$ pure products, as the number of components increases, the number of possible simple column configurations sharply increases. Therefore, the design and optimization of a distillation column involves the selection of the configuration and the operating conditions to minimize the total investment and operation cost (Yeomans \& Grossmann, 2000). The global optimization of a complex distillation system is usually characterized as being of large problem size, since the significant number of strongly nonlinear equations results in serious difficulty in solving the model. Moreover, good initial values are needed for solving the NLP subproblems. Until now, several strategies have been proposed to address this optimization problem. For example, Andrecovich \& Westerberg (1985) proposed a mixed-integer linear programming (MILP) model for synthesizing sharp separation sequences. Later, Paules \& Floudas (1990) and Aggarwal \& Floudas (1990) developed mixed-integer nonlinear programming (MINLP) models for heat-integrated and nonsharp distillation sequences using linear mass balances. In other study, Novak et al. (1996) proposed superstructure MINLP optimization approaches using short-cut models for heat-integrated distillation. Smith \& Pantelides (1995) and Bauer \& Stichlmair (1998) developed MINLP models using rigorous tray-by-tray models for zeotropic and azeotropic mixtures. Also, Dunnebier \& Pantelides (1999) have used rigorous tray-by-tray MINLP models to solve complex column configuration 
distillation sequences. So far, most of the available mathematical programming models are based on simplified performance models of the distillation columns, including linear mass balance equations, short-cut models, and aggregated models (see for example, Papalexandri \& Pistikopoulos, 1996; Caballero \& Grossmann, 1999). While some of these methods can provide useful results in terms of preliminary designs or bounds for process synthesis, it is clear that it would be desirable to directly incorporate rigorous models in the design procedures in order to increase their industrial relevance and scope of application, particularly, for nonideal mixtures. Regarding the rigorous MINLP synthesis models by Bauer \& Stichlmair (1998), Smith \& Pantelides (1995), and Dünnebier \& Pantelides (1999), all of them use modifications of the single-column MINLP model proposed by Viswanathan \& Grossmann (1993) for optimizing the feed tray location and number of trays. These rigorous MINLP synthesis models exhibit significant computational difficulties such as the introduction of equations that can become singular, the solution of many redundant equations, and the requirement of a good initialization point. So, the presence of nonlinearities and nonconvexities in the MESH equations and thermodynamic equilibrium equations, as well as the convergence difficulties when deleting non-existing columns or column sections, are common problems to the tray-by-tray models based on the model by Viswanathan \& Grossmann (1993). In summary, these difficulties translate into high computational times and the requirement of good initial guesses and bounds on the design variables to achieve model convergence.

In general, the optimal design of distillation systems is a highly non-linear and multivariable problem, with the presence of both continuous and discontinuous design variables. In addition, the objective function used as optimization criterion is generally non-convex with several local optimums and subject to several constraints. The use of stochastic optimizers, which deals with multi-modal and non-convex problems, can be an effective way to face the challenging characteristics involved in the design of distillation columns. Stochastic global optimization algorithms are capable of solving, robustly and efficiently, the challenging multi-modal optimization problem, and they appear to be a suitable alternative for the design and optimization of complex separation schemes (Martínez-Iranzo et al., 2009). These optimization methods have several features that make them attractive for solving optimization problems with modular simulators, where the model of each unit is only available in an implicit form (i.e., black-box model). First, due to the fact that they are based on direct search strategies, it is not necessary to have explicit information on the mathematical model or its derivatives. Secondly, the search for the optimal solution is not limited to one point but rather relies on several points simultaneously; therefore, the knowledge of initial feasible points is not required.

In this chapter, we have implemented several stochastic global optimization methods to obtain the design and optimization of three distillation sequences: multicomponent conventional distillation system (Figure 1), thermally coupled reactive scheme with side stripper (Figure 2), and a dividing wall distillation column (Figure 3). Specifically, these stochastic optimization methods are: Simulated Annealing (SA), Harmony Search (HS) and Genetic Algorithms (GA). In recent years, the range of applicability of optimization has been widened and progress has improved in different areas. Effective search methods, such as genetic algorithms, simulated annealing and harmony search, for global optimization have been developed, and problems with complex analysis model and various types of constraints and non-convex objective functions have been investigated (Costa et al., 2000). 


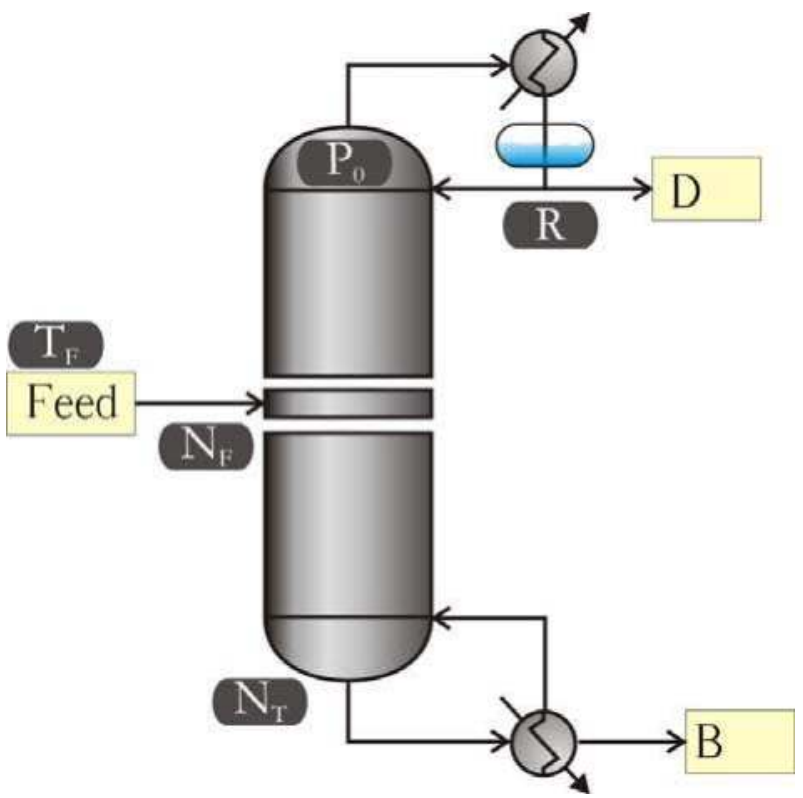

Fig. 1. Schematic representation of a multicomponent conventional distillation column. Nomenclature of this figure is given in section 8 of this chapter.

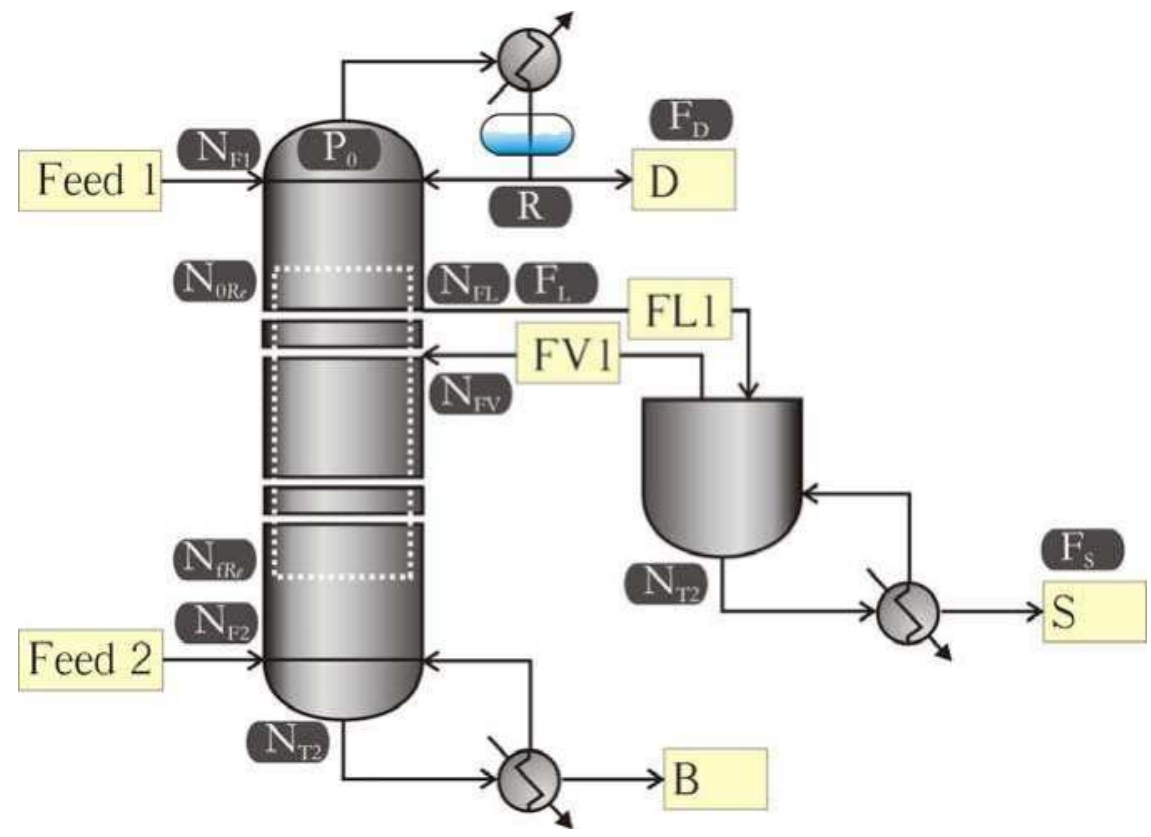

Fig. 2. Schematic representation of a thermally coupled reactive distillation sequence with side stripper (TCRDS-SS). Nomenclature of this figure is given in section 8 of this chapter. 


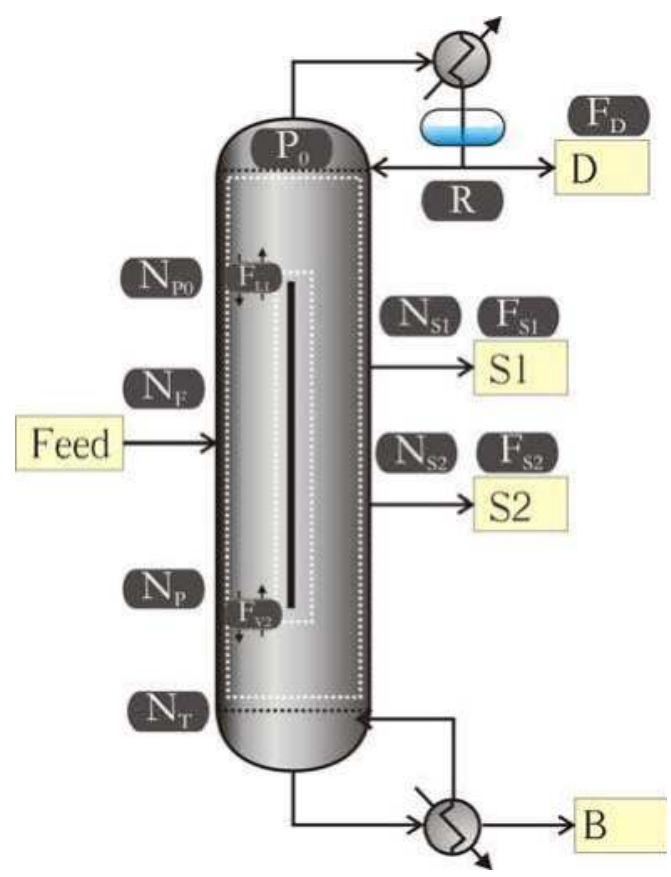

Fig. 3. Schematic representation of a dividing wall distillation column (DWC). Nomenclature of this figure is given in section 8 of this chapter.

We select SA, HS and GA for this study because they have shown their merits in large-scale search, approaching the global optimum quickly and steadily. These optimization methods have several features that make them attractive for solving optimization problems with modular simulators, where the model of each unit is only available in an implicit form.

On the other hand, literature indicates that, when operating conditions are properly chosen, the thermally coupled reactive scheme with side stripper and dividing wall distillation column can produce important energy savings compared with conventional distillation sequences (Kiss et al., 2010). Some studies have demonstrated that this kind of sequences has energy savings of about 30\% over conventional schemes (Triantafyllou \& Smith, 1992; Hernández \& Jiménez, 1996). Therefore, we have studied the design of these distillation schemes using stochastic global optimization methods coupled to the Aspen One Aspen Plus process simulator for the evaluation of the objective function, ensuring that all results obtained are rigorous. To the best of our knowledge, the evaluation and comparison of stochastic global optimization methods have not been reported for process design of distillation configurations. Therefore, our results permit to identify the capabilities and limitations of these optimization strategies in the process design applications.

\section{Description of stochastic global optimization methods used for the design of distillation schemes}

Stochastic optimization methods are optimization algorithms which incorporate probabilistic (i.e., random) elements to diversify and intensify the search space of decision 
variables. Further, the injected randomness may provide the necessary impetus to move away from a local solution when searching for a global optimum. Stochastic optimization methods of this kind include: simulated annealing, harmony search, swarm intelligence (e.g., ant colony optimization, particle swarm optimization), evolutionary algorithms (e.g., genetic algorithms, differential evolution), among others. In this study, we use three optimization methods: Simulated Annealing (SA), Genetic Algorithms (GA) and Harmony Search (HS). Note that SA and GA are classical stochastic optimization methods and have been used for process design (Vazquez-Castillo et al., 2009), while HS is a novel stochastic optimization method with few chemical engineering applications (Geem, 2009). In general, all methods have the attributes of a good optimization strategy such as generality, efficiency, reliability and ease of use. A brief description of these algorithms is provided in the following section.

\subsection{Simulated annealing}

Simulated annealing mimics the thermodynamic process of cooling of molten metals to attain the lowest free energy state (Kirkpatrick et al., 1983). Starting with an initial solution, the algorithm performs a stochastic partial search of the space defined for decision variables. In minimization problems, uphill moves are occasionally accepted with a probability controlled by the parameter called annealing temperature: $\mathrm{T}_{\mathrm{SA}}$. The probability of acceptance of uphill moves decreases as $\mathrm{T}_{\mathrm{SA}}$ decreases. At high $\mathrm{T}_{\mathrm{SA}}$, the search is almost random, while at low $\mathrm{T}_{\mathrm{SA}}$ the search becomes selective where good moves are favored. The core of this algorithm is the Metropolis criterion (Metropolis et al., 1983), which is used to accept or reject uphill movements with an acceptance probability given by

$$
M\left(T_{S A}\right)=\min \left\{1, \exp \left(\frac{-\Delta f}{T_{S A}}\right)\right\}
$$

where $\Delta \mathrm{f}$ is the change in objective function value from the current point to new point.

The objective function is evaluated at the trial point, and its value is compared to the objective value at the starting/current point. Eq. (1) is used to accept or reject the trial point. If this trial point is accepted, the algorithm continues the search using that point; otherwise, another trial point is generated within the neighborhood of the starting/current point. A fall in $T_{S A}$ is imposed upon the system using a proper cooling schedule. Thus, as $T_{S A}$ declines, downhill moves are less likely to be accepted and SA focuses on the most promising area for optimization. These iterative steps are performed until the specified stopping criterion is satisfied. Figure 4 shows a flowchart of this algorithm. Until now, SA algorithm has been successfully used in several chemical engineering application (e.g., Rangaiah, 2001; BonillaPetriciolet et al., 2006; Wei-Zhong \& Xi-Gang, 2009). In our work, we have used the SA subroutine of MATLAB $\AA$.

The random numbers rand can be uniformly distributed in the interval [0, 1]. If rand < $\mathrm{M}\left(\mathrm{T}_{\mathrm{SA}}\right)$, the trial point is accepted, otherwise the starting/current point is used to start the next step. The temperature $\mathrm{T}_{\mathrm{SA}}$ can be considered a control parameter. The initial temperature $\mathrm{Ti}$ is related with the standard deviation of the random perturbation and the final temperature $T_{f}$, with the order of magnitude of the desired accuracy, will give the location of the optimum solution. 


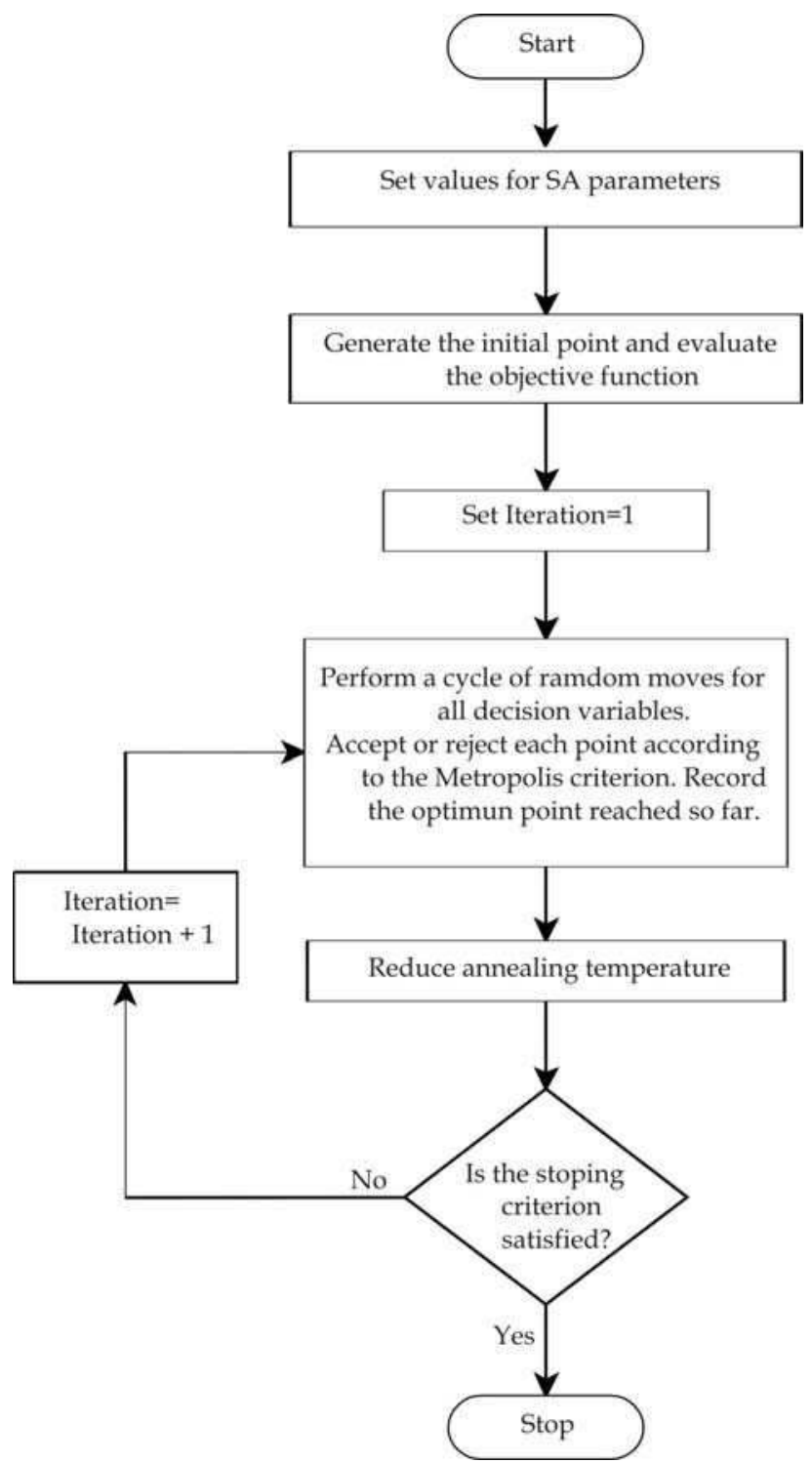

Fig. 4. Flowchart of Simulated Annealing stochastic optimization method.

\subsection{Genetic Algorithm}

Genetic algorithm (GA) is a stochastic technique that simulates natural evolution on the solution space of the optimization problems. It operates on a population of potential solutions (i.e., individuals) in each iteration (i.e., generation). By combining some individuals of the current population according to predefined operations, a new population that contains better individuals is produced as the next generation. The first step of GA is to 
create randomly an initial population of $\mathrm{N}_{\text {pop }}$ solutions in the feasible region. GA works on this population and combines (crossover) and modifies (mutation) some chromosomes according to specified genetic operations, to generate a new population with better characteristics. Individuals for reproduction are selected based on their objective function values and the Darwinian principle of the survival of the fittest (Holland, 1975). Genetic operators are used to create new individuals for the next population from those selected individuals of the current population, and they serve as searching mechanisms in GA. In particular, crossover forms two new individuals by first choosing two individuals from the mating pool (containing the selected individuals) and then swapping different parts of genetic information between them. This combining (crossover) operation takes place with a user-defined crossover probability $\left(\mathrm{P}_{\text {cros }}\right)$ so that some parents remain unchanged even if they are chosen for reproduction. Mutation is a unary operator that creates a new solution by a random change in an individual. It provides a guarantee that the probability of searching any given string will never be zero and acting as a safety net to recover good genetic material which may be lost through the action of selection and crossover. The mutation procedure proceeds with a probability $\mathrm{P}_{\text {mut }}$. Selection, crossover and mutation procedures are recursively used to improve the population and to identify promising areas for optimization. This algorithm terminates when the user-specified criterion is satisfied. Usually, GA stops after evolving for the specified number of generations ( $\left.\operatorname{Gen}_{\max }\right)$. The GA subroutine used in this study is from the OptimToolbox of MATLAB®. Details about the GA strategy and applications can be found in Holland (1975) and Figure 5 provides the corresponding general flowchart of GA.

\subsection{Harmony Search}

Harmony Search (HS) was first developed by Geem et al. (2001). This relatively new heuristic optimization algorithm has been applied to solve many optimization problems, e.g.: benchmark optimization problems, water distribution network, groundwater modeling, energy-saving dispatch, among others. HS is a music-based metaheuristic optimization algorithm and is inspired by the observation that the aim of music is to search for a perfect state of harmony (Geem, 2009). This harmony in music is analogous to find the optimal solution in an optimization process.

Like genetic algorithms and particle swarm optimization, harmony search is not a gradientbased search, so it avoids most of the pitfalls of any gradient-based search algorithms. Thus, it has fewer mathematical requirements and, subsequently, can be used to deal with complex objective functions with continuous or discontinuous and linear or nonlinear constraints. On the other hand, harmony search could be potentially more efficient than genetic algorithms because harmony search does not use binary encoding and decoding, but it has multiple solution vectors. Therefore, HS can be faster during each iteration and its implementation is also easier.

HS can be explained in more detail with the aid of the discussion of the improvisation process by a musician. When a musician is improvising, he or she has three possible choices: (1) play any piece of music (a series of pitches in harmony) exactly from his or her memory; (2) play something similar to a known piece (thus adjusting the pitch slightly); or (3) compose new or random notes. If we formalize these three options for optimization, we have three corresponding components: usage of harmony memory, pitch adjusting, and randomization. 


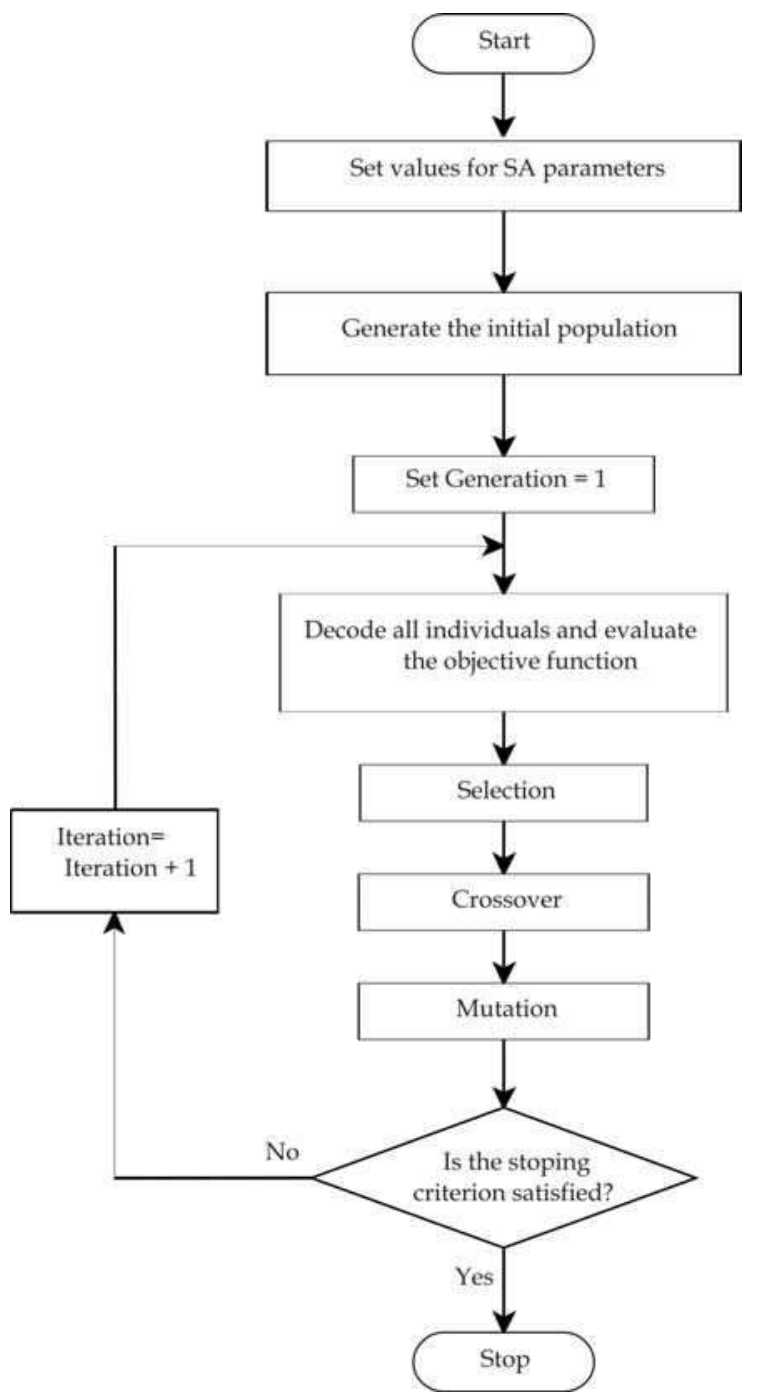

Fig. 5. Flowchart of Genetic Algorithm stochastic optimization method.

The use of harmony memory is important in HS as it is similar to choose the best fit individuals in the genetic algorithms. This will ensure that the best harmonies will be carried over to the new harmony memory. In order to use this memory more effectively, we can assign a parameter $r_{a c c e p t} \in[0,1]$, called harmony memory accepting or considering rate. If this rate is too low, only few best harmonies are selected and it may converge too slowly. If this rate is extremely high (i.e., near to 1), almost all the harmonies are used in the harmony memory, then other harmonies are not explored well, leading to potential local solutions. Therefore, typically, $r_{\text {accept }}=0.7 \sim 0.95$ is used in the context of global optimization (Yang, 2008). 


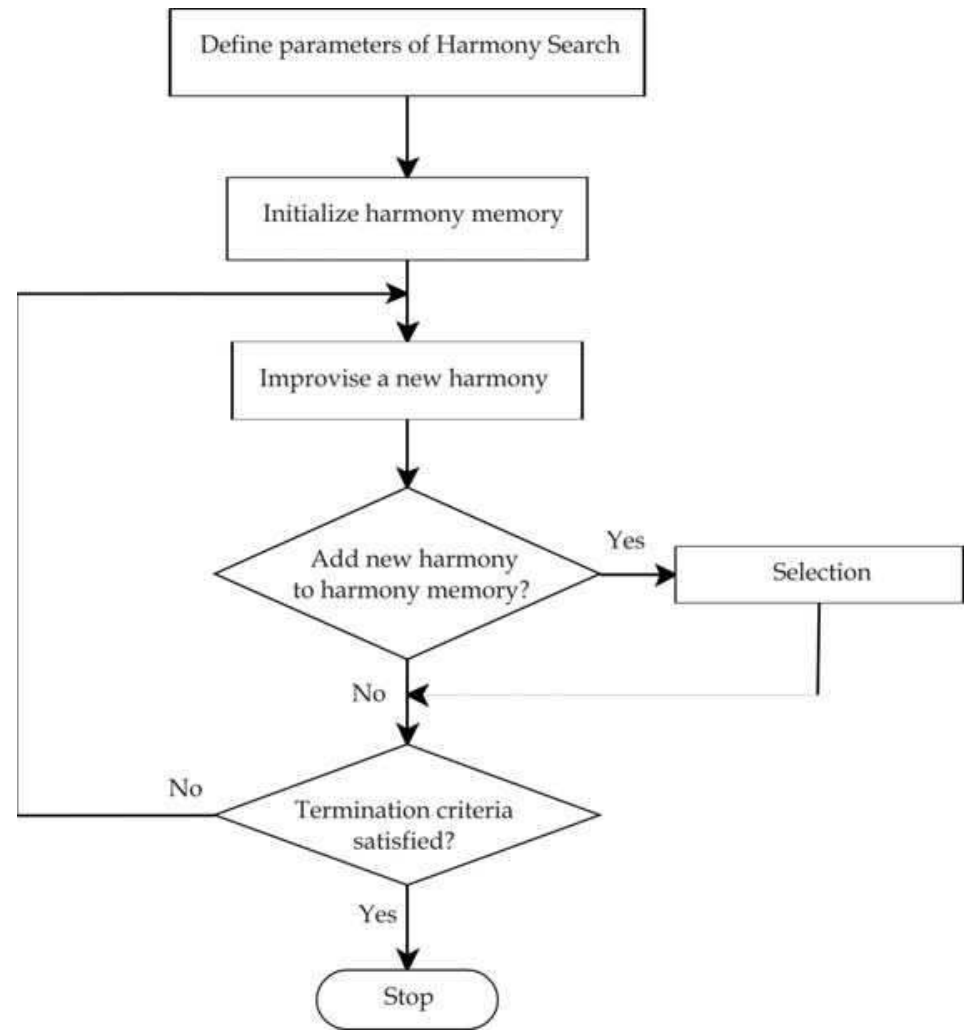

Fig. 6. Flowchart of Harmony Search stochastic optimization method.

Several authors also recommend to adjust the pitch slightly in the second component. In theory, the pitch can be adjusted linearly or non-linearly, but in practice, linear adjustment is used. So, we have

$$
x_{\text {new }}=x_{\text {lower limit }} \pm x_{\text {range }} \text { * rand }
$$

where $x_{\text {range }}=x_{\text {upper limit }}-x_{\text {lower limit }}$ and rand is a random number generator in the range of 0 a 1 . Pitch adjustment is similar to the mutation operator in genetic algorithms. We can assign a pitch-adjusting rate $\left(r_{p a}\right)$ to control the degree of the adjustment. For example, if $r_{p a}$ is too low, then there is rarely any change. If it is too high, the algorithm may not converge at all. Thus, it is usually recommended to use $r_{p a}=0.1 \sim 0.5$. In this work, $r_{a c c e p t}=0.8$ and $r_{p a}=0.4$ have been used.

The third component is the randomization, which is used to increase the diversity of the solutions. Although adjusting pitch has a similar role, but it is limited to certain local pitch adjustment and thus corresponds to a local search. The use of randomization can drive the system further to explore various diverse solutions so as to find the global optimum. The three components in harmony search can be summarized in the flowchart shown in Figure 6. Note that the probability of randomization is $p_{\text {random }}=1-p_{\text {accept }}$, and the actual probability of pitch-adjusting is $p_{p i t c h}=r_{a c c e p t}{ }^{*} r_{p a}$. We have used a HS subroutine implemented in MATLAB囚. 


\section{Optimization strategy}

In order to optimize the complex distillation sequences described in the introduction, we used SA, GA and HS coupled to Aspen ONE Aspen Plus. Specifically, for process design of complex separation schemes, the optimization of heat duty of the column is the optimization target. This design problem is a challenging global optimization problem with continuous and discontinuous decision variables. The formulation of optimization problems for the design of separation schemes is given below.

For the multicomponent distillation column used in the hydrodesulfurization (HDS) process, the optimization of the heat duty of the column can be stated as

$$
\begin{aligned}
& \operatorname{Min}(Q)=f\left(R, P_{0}, T_{F}, N_{F}, N_{T}\right) \\
& \text { subject to } \\
& \vec{y}_{m} \geq \vec{x}_{m}
\end{aligned}
$$

where $R$ is the reflux ratio, $P_{0}$ is the column pressure, $T_{F}$ is the feed temperature, NF is the number of the feed stage and $N_{T}$ is the number of stages of column. Note that $y_{m}$ and $x_{m}$ are vectors of obtained and required purities for the m components, respectively.

In the thermally coupled reactive distillation (TCRDS-SS), the global optimization problem for the minimization of the heat duty of the sequence is defined as

$$
\begin{aligned}
& \operatorname{Min}(Q)=f\left(R, P_{0}, F_{D}, F_{S}, F_{L}, N_{F 1}, N_{F 2}, N_{0 R e}, N_{f R e}, N_{F L}, N_{F V}, N_{T 1}, N_{T 2}\right) \\
& \text { subject to } \\
& \vec{y}_{m} \geq \vec{x}_{m}
\end{aligned}
$$

where $\mathrm{R}$ is the reflux ratio, $\mathrm{P}_{0}$ is the main column pressure, $\mathrm{F}_{\mathrm{D}}$ and $\mathrm{F}_{\mathrm{S}}$ are the distillate and side fluxes, $F_{L}$ and $N_{F L}$ are the value and location of the interconnection flow, $N_{F 1}$ and $N_{F 2}$ are the number of the feed stages, $\mathrm{N}_{\mathrm{FV}}$ is the stream vapor tray location, $\mathrm{N}_{0 \mathrm{Re}}$ and $\mathrm{N}_{\mathrm{fRe}}$ are the first and last reaction tray location, $\mathrm{N}_{\mathrm{T} 1}$ and $\mathrm{N}_{\mathrm{T} 2}$ are the number of stages of the main column and stripper, $\mathrm{y}_{\mathrm{m}}$ and $\mathrm{x}_{\mathrm{m}}$ are vectors of obtained and required purities for the $\mathrm{m}$ components, respectively.

In DWC, the global optimization problem is given by

$$
\begin{aligned}
& \operatorname{Min}(Q)=f\left(R, P_{0}, F_{D}, F_{S 1}, F_{S 2}, F_{L 1}, F_{V 2}, N_{F}, N_{P 0}, N_{p}, N_{S 1}, N_{S 2}, N_{T}\right) \\
& \text { subject to } \\
& \vec{y}_{m} \geq \vec{x}_{m}
\end{aligned}
$$

where $R$ is the reflux ratio, $P_{0}$ is the main column pressure, $F_{D}$ is the distillate flux, $F_{S 1}$ and $F_{S 2}$ are the side fluxes, $\mathrm{F}_{\mathrm{L} 1}$ and $\mathrm{F}_{\mathrm{V} 2}$ are the values of liquid and vapor interconnection flows, $\mathrm{N}_{\mathrm{F}}$ is the feed stage, $N_{P 0}$ and $N_{p}$ are the first and last prefractioner tray location, $N_{S 1}$ and $N_{S 2}$ are the side stream tray location, $\mathrm{y}_{\mathrm{m}}$ and $\mathrm{x}_{\mathrm{m}}$ are vectors of obtained and required purities for the $\mathrm{m}$ components, respectively. In summary, these global optimization problems have been used for comparing the performance of SA, GA and HS in the design of complex distillation sequences.

\section{Case of study}

To compare the performance of stochastic optimization methods, we have analyzed three case studies. First, we analyze the design of the multicomponent distillation column used in 
the hydrodesulfurization (HDS) process. The feed composition is showed in the Table 1. Note that this composition of the diesel is reported by Viveros-García et al. (2005). The design objective is to obtain in the top of the column thiophene and benzothiophene with $2.13 \%$ and $1.29 \%$ in mole composition, respectively, and in the bottom dibenzothiophene and 4,6-dimethyldebenzothiphene with $16.0 \%$ and 3.2\% mole composition, respectively. For this class of systems, thermodynamic model such as Peng-Robinson EoS can be used to calculate the vapor-liquid equilibrium.

Then, we analyze the design of a TCRDS-SS to obtain biodiesel (i.e., the esterification of methanol and lauric acid). The systems include two feed streams; the first is lauric acid with a flow of $45.4 \mathrm{kmol} / \mathrm{h}$ as saturated liquid at $1.5 \mathrm{bar}$, and the second is methanol with a flow of $54.48 \mathrm{kmol} / \mathrm{h}$ as saturated vapor at $1.5 \mathrm{bar}$.

\begin{tabular}{cc}
\hline Component & Mole Fraction \\
\hline Thiophene & 0.008 \\
Benzothiophene & 0.008 \\
n-Undecane & 0.489 \\
n-Dodecane & 0.316 \\
n-Tridecane & 0.008 \\
n-Tetradecane & 0.001 \\
n-Hexadecane & 0.05 \\
Dibenzothiophene & 0.1 \\
4,6-dimethyldibenzothiophene & 0.02 \\
\hline
\end{tabular}

Table 1. Feed composition in distillation column of the HDS process used as case of study.

The design objective is a process for high-purity fatty ester, over $99.9 \%$ mass fraction, which is suitable for biodiesel application. It is important to highlight that this equilibrium reaction is usually catalyzed using sulfuric acid or p-toluensulfonic acid. The kinetic model (see Table 2) reported in Steinigeweg \& Gmehling (2003) was used. For this class of reactive systems, thermodynamic model such as UNIFAC can be used to calculate the vapor-liquid or vapor-liquid-liquid equilibrium.

Kinetic parameters

\begin{tabular}{ccc}
\hline Reaction & $\mathrm{K}_{\mathrm{i}}(\mathrm{mol} / \mathrm{g} \mathrm{s})$ & $\mathrm{E}_{\mathrm{A}, \mathrm{i}}(\mathrm{kJ} / \mathrm{mol})$ \\
\hline Esterification & $9.1164 \times 10^{5}$ & 68.71 \\
Hydrolysis & $1.4998 \times 10^{4}$ & 64.66 \\
\hline
\end{tabular}

Table 2. Kinetic parameters for the pseudo-homogeneous kinetic model of the esterification reaction.

Finally, we have studied the design of a DWC for purification of a mixture of alcohols: nbutanol, 1-pentanol, 1-hexanol, and 1-heptanol. The feed flowrate is $100 \mathrm{kmol} / \mathrm{h}$ and the feed is introduced in the column as saturated liquid. The composition in the feed flowrate is $40,10,10,40$ in mole percent. The design objective is to obtain each alcohol with high purity (98.6, 98, 98, 98.5 in mole composition percent). For this class of systems, thermodynamic model such as NRTL can be used to calculate the vapor-liquid equilibrium.

Both the tuning process parameters for each one and boundary variables searched were tuned using several short tests for improve the efficiency in the methods. Table 3 shows the limits of the search variables that have been established. The parameter tuning and search 


\begin{tabular}{|c|c|}
\hline Schemes & Boundaries \\
\hline \multirow[t]{5}{*}{ HDS } & $\mathrm{R}=[0.110]$ \\
\hline & $P_{0}=\left[\begin{array}{ll}1 & 10\end{array}\right] \mathrm{atm}$ \\
\hline & $\mathrm{T}_{\mathrm{F}}=[298478] \mathrm{K}$ \\
\hline & $\mathrm{N}_{\mathrm{F}}=\left[\begin{array}{ll}2 & 99\end{array}\right]$ \\
\hline & $\mathrm{N}_{\mathrm{T}}=\left[\begin{array}{ll}3 & 100\end{array}\right]$ \\
\hline \multirow[t]{13}{*}{ TCRDS-SS } & $\mathrm{R}=\left[\begin{array}{ll}10 & 20\end{array}\right]$ \\
\hline & $P_{0}=\left[\begin{array}{ll}1 & 5\end{array}\right] \mathrm{atm}$ \\
\hline & $\mathrm{F}_{\mathrm{D}}=[8.899 .53] \mathrm{kmol} / \mathrm{h}$ \\
\hline & 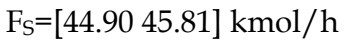 \\
\hline & $\mathrm{F}_{\mathrm{L}}=[49.8956 .70] \mathrm{kmol} / \mathrm{h}$ \\
\hline & $\mathrm{N}_{\mathrm{F} 1}=[298]$ \\
\hline & $\mathrm{N}_{\mathrm{F} 2}=\left[\begin{array}{ll}3 & 99\end{array}\right]$ \\
\hline & $\mathrm{N}_{0 \mathrm{Re}}=\left[\begin{array}{ll}2 & 99\end{array}\right]$ \\
\hline & $\mathrm{N}_{\mathrm{fRe}}=\left[\begin{array}{ll}3 & 100\end{array}\right]$ \\
\hline & $\mathrm{N}_{\mathrm{FL}}=\left[\begin{array}{ll}6 & 98\end{array}\right]$ \\
\hline & $\mathrm{N}_{\mathrm{FV}}=\left[\begin{array}{ll}7 & 99\end{array}\right]$ \\
\hline & $\mathrm{N}_{\mathrm{T} 1}=\left[\begin{array}{ll}5 & 100\end{array}\right]$ \\
\hline & $\mathrm{N}_{\mathrm{T} 2}=[250]$ \\
\hline \multirow[t]{13}{*}{$\overline{D W C}$} & $\mathrm{R}=[5575]$ \\
\hline & $P_{0}=\left[\begin{array}{ll}1 & 5\end{array}\right] \mathrm{atm}$ \\
\hline & $\mathrm{F}_{\mathrm{D}}=[3941] \mathrm{kmol} / \mathrm{h}$ \\
\hline & $\mathrm{F}_{\mathrm{S} 1}=\left[\begin{array}{ll}9 & 10\end{array}\right] \mathrm{kmol} / \mathrm{h}$ \\
\hline & $\mathrm{F}_{\mathrm{S} 2}=\left[\begin{array}{ll}9 & 10\end{array}\right] \mathrm{kmol} / \mathrm{h}$ \\
\hline & $\mathrm{F}_{\mathrm{L} 1}=\left[\begin{array}{lll}100 & 300\end{array}\right] \mathrm{kmol} / \mathrm{h}$ \\
\hline & $\mathrm{F}_{\mathrm{V} 2}=[200600] \mathrm{kmol} / \mathrm{h}$ \\
\hline & $\mathrm{N}_{\mathrm{F}}=\left[\begin{array}{lll}26 & 147\end{array}\right]$ \\
\hline & $\mathrm{N}_{\mathrm{P} 0}=\left[\begin{array}{ll}21 & 144\end{array}\right]$ \\
\hline & $N_{P}=\left[\begin{array}{ll}25 & 148\end{array}\right]$ \\
\hline & $\mathrm{N}_{\mathrm{S} 1}=\left[\begin{array}{ll}33 & 146\end{array}\right]$ \\
\hline & $\mathrm{N}_{\mathrm{S} 2}=\left[\begin{array}{ll}34 & 147\end{array}\right]$ \\
\hline & $\mathrm{N}_{\mathrm{T}}=\left[\begin{array}{ll}30 & 150\end{array}\right]$ \\
\hline
\end{tabular}

Table 3. Values of boundary limits.

limits improve the convergence of stochastic methods. Our study established an initial temperature of 100 and linear temperature profile during the cooling stage for SA. We use default values for the parameters of the genetic algorithm as proposed in the Toolbox of MatLab. To improve the solution, we used populations with 100 individual in each iteration. We have used a harmony memory of 10 individuals (see Table 4).

\section{Results}

Table 5 shows the results obtained for the design of complex distillation sequences using stochastic optimization methods and different values of function evaluations (NFE). Specifically, in Table 5 we report the average and standard deviation of the heat duty of each sequence. For all stochastic methods, the mean value of objective function (i.e., heat duty) decreased as the NFE increased and, as expected, the performance of stochastic 


\begin{tabular}{clll}
\hline $\begin{array}{c}\text { Stochastic } \\
\text { Method }\end{array}$ & \multicolumn{1}{c}{ GA } & \multicolumn{1}{c}{ HS } & \multicolumn{1}{c}{$S A$} \\
\hline \multirow{5}{*}{ Parameters } & Population size: 100 & & Annealing function: \\
& Fitness scaling: Rank & & Boltzman \\
& Selection: Stochastic & Harmony memory $=10$ & Reannealing interval= \\
& uniform & harmony accepting $=0.8$ & 100 \\
& Crossover: Scattered & Pitch adjusting $=0.4$ & Temperature update: \\
& Crossover fraction=0.8 & & linear \\
& Mutation: Uniform & Initial temperature $=100$ \\
\hline
\end{tabular}

Table 4. Values of parameters used in stochastic methods

\begin{tabular}{cllll} 
& \multicolumn{4}{c}{ Mean heat duty of the sequence \pm standard deviation $(\mathrm{kW})$} \\
\hline \multicolumn{1}{c}{ Scheme } & \multicolumn{1}{c}{ NFE } & \multicolumn{1}{c}{ GA } & \multicolumn{1}{c}{ HS } & \multicolumn{1}{c}{ SA } \\
\hline HDS & 1,000 & $884.98 \pm 118.59$ & $845.69 \pm 56.39$ & $\mathbf{7 9 3 . 6 7 \pm 5 5 . 1 3}$ \\
& 10,000 & $750.83 \pm 14.20$ & $746.43 \pm 24.01$ & $\mathbf{7 3 9 . 8 6} \pm \mathbf{1 3 . 3 8}$ \\
TCRDS-SS & 10,000 & $1,981.28 \pm 128.90$ & $1,916.42 \pm 79.39$ & $\mathbf{1 , 8 5 1 . 7 1 \pm 7 7 . 3 8}$ \\
& 20,000 & $1,702.37 \pm 85.79$ & $1,691.83 \pm 37.27$ & $\mathbf{1 , 6 4 1 . 9 5 \pm 6 6 . 3 2}$ \\
DWC & 10,000 & $31,311.01 \pm 867.72$ & $\mathbf{2 6 , 8 8 7 . 3 8} \pm 9, \mathbf{0 1 0 . 1 3}$ & $28,852.35 \pm 1,080.74$ \\
& 20,000 & $29,284.32 \pm 1,561.35$ & $\mathbf{2 4 , 7 3 5 . 5 8 \pm 8 , 2 7 7 . 2 9}$ & $27,194.80 \pm 1,134.84$ \\
\hline
\end{tabular}

Table 5. Mean and standard deviation of heat duty of distillation sequences using stochastic optimization methods

methods increases as NFE increases. Note that SA outperformed the HS and GA in solving global optimization for the design of HSD and TCRDS-SS, while HS is better in the design of DWC, see results reported in Table 5. Overall, GA showed the worst solutions for the design of all distillation sequences.

On the other hand, Table 6 shows that the design parameters (e.g., pressure, reflux ratio, number of stages) are consistent with the design heuristics applied for this type of distillation sequence. In other words, the optimum designs obtained by using these optimization techniques, for complex distillation columns, are likely to be implemented at industrial level. In general, the results show that for the optimization of this type of complex distillation columns, SA is the best alternative. The CPU time needed to solve distillation systems using Aspen ONE Aspen Plus are 10800 seconds for 1000 NFE in multicomponent distillation process, and 345000 seconds for 20000 NFE in thermally coupled reactive distillation in a $2.5 \mathrm{GHz}$ Intel (R) Core (TM)2 Quad computer. In particular, significant CPU time is expended on finding feasible points from random initial estimates and the convergence time of the simulator Aspen ONE Aspen Plus for each calculation in the function evaluated. In general, the CPU time of SA is faster than GA and HS in design problems of complex distillation sequences.

\section{Conclusion}

In this study, the performance of SA, GA, and HS has been tested and compared in the design of complex distillation columns. To our knowledge, reports on a comparative study about the use of these methods in complex distillation scheme optimization have not been reported. The performance of the stochastic optimization methods tested varies significantly 


\begin{tabular}{|c|c|c|c|}
\hline & \multicolumn{3}{|c|}{ Design variables } \\
\hline Schemes & $G A$ & $H S$ & $S A$ \\
\hline \multirow{6}{*}{ HDS } & $\mathrm{R}=2.29$ & $\mathrm{R}=2.29$ & $\mathrm{R}=2.29$ \\
\hline & $\mathrm{P}_{0}=2.29 \mathrm{~atm}$ & $\mathrm{P}_{0}=1.00 \mathrm{~atm}$ & $\mathrm{P}_{0}=1.00 \mathrm{~atm}$ \\
\hline & $\mathrm{T}_{\mathrm{F}}=478 \mathrm{~K}$ & $\mathrm{~T}_{\mathrm{F}}=478 \mathrm{~K}$ & $\mathrm{~T}_{\mathrm{F}}=477.84 \mathrm{~K}$ \\
\hline & $\mathrm{N}_{\mathrm{F}}=60$ & $\mathrm{~N}_{\mathrm{F}}=87$ & $\mathrm{~N}_{\mathrm{F}}=88$ \\
\hline & $\mathrm{N}_{\mathrm{T}}=67$ & $\mathrm{~N}_{\mathrm{T}}=93$ & $\mathrm{~N}_{\mathrm{T}}=94$ \\
\hline & $\mathrm{Q}_{\mathrm{T}}=752.52 \mathrm{~kW}$ & $\mathrm{Q}_{\mathrm{T}}=725.02 \mathrm{~kW}$ & $\mathrm{Q}_{\mathrm{T}}=727.06 \mathrm{~kW}$ \\
\hline \multirow[t]{14}{*}{ TCRDS-SS } & $\mathrm{R}=21.24$ & $\mathrm{R}=15.00$ & $\mathrm{R}=12.02$ \\
\hline & $\mathrm{P}_{0}=3.78 \mathrm{~atm}$ & $\mathrm{P}_{0}=1.31 \mathrm{~atm}$ & $\mathrm{P}_{0}=1.08 \mathrm{~atm}$ \\
\hline & $\mathrm{F}_{\mathrm{D}}=9.39 \mathrm{kmol} / \mathrm{h}$ & $\mathrm{F}_{\mathrm{D}}=8.48 \mathrm{kmol} / \mathrm{h}$ & $\mathrm{F}_{\mathrm{D}}=8.89 \mathrm{kmol} / \mathrm{h}$ \\
\hline & $\mathrm{F}_{\mathrm{S}}=45.32 \mathrm{kmol} / \mathrm{h}$ & $\mathrm{F}_{\mathrm{S}}=45.80 \mathrm{kmol} / \mathrm{h}$ & $\mathrm{F}_{\mathrm{S}}=45.39 \mathrm{kmol} / \mathrm{h}$ \\
\hline & $\mathrm{F}_{\mathrm{L}}=50.05 \mathrm{kmol} / \mathrm{h}$ & $\mathrm{F}_{\mathrm{L}}=56.42 \mathrm{kmol} / \mathrm{h}$ & $\mathrm{F}_{\mathrm{L}}=56.31 \mathrm{kmol} / \mathrm{h}$ \\
\hline & $\mathrm{N}_{\mathrm{F} 1}=5$ & $\mathrm{~N}_{\mathrm{F} 1}=31$ & $\mathrm{~N}_{\mathrm{F} 1}=34$ \\
\hline & $\mathrm{N}_{\mathrm{F} 2}=45$ & $\mathrm{~N}_{\mathrm{F} 2}=47$ & $\mathrm{~N}_{\mathrm{F} 2}=74$ \\
\hline & $\mathrm{N}_{0 \operatorname{Re}}=48$ & $\mathrm{~N}_{0 R \mathrm{e}}=34$ & $\mathrm{~N}_{0 R \mathrm{Re}}=4$ \\
\hline & $\mathrm{N}_{\mathrm{fRe}}=50$ & $\mathrm{~N}_{\mathrm{fRe}}=47$ & $\mathrm{~N}_{\mathrm{fRe}}=83$ \\
\hline & $\mathrm{N}_{\mathrm{FL}}=20$ & $\mathrm{~N}_{\mathrm{FL}}=30$ & $\mathrm{~N}_{\mathrm{FL}}=10$ \\
\hline & $\mathrm{N}_{\mathrm{FV}}=20$ & $\mathrm{~N}_{\mathrm{FV}}=22$ & $\mathrm{~N}_{\mathrm{FV}}=37$ \\
\hline & $\mathrm{N}_{\mathrm{T} 1}=50$ & $\mathrm{~N}_{\mathrm{T} 1}=47$ & $\mathrm{~N}_{\mathrm{T} 1}=94$ \\
\hline & $\mathrm{N}_{\mathrm{T} 2}=22$ & $\mathrm{~N}_{\mathrm{T} 2}=19$ & $\mathrm{~N}_{\mathrm{T} 2}=20$ \\
\hline & $\mathrm{Q}_{\mathrm{T}}=1,583.84 \mathrm{~kW}$ & $\mathrm{Q}_{\mathrm{T}}=1,645.27 \mathrm{~kW}$ & $\mathrm{Q}_{\mathrm{T}}=1,531.25 \mathrm{~kW}$ \\
\hline \multirow[t]{14}{*}{ DWC } & $\mathrm{R}=61.39$ & $\mathrm{R}=56.88$ & $\mathrm{R}=56.40$ \\
\hline & $\mathrm{P}_{0}=3.77 \mathrm{~atm}$ & $\mathrm{P}_{0}=3.68 \mathrm{~atm}$ & $\mathrm{P}_{0}=3.14 \mathrm{~atm}$ \\
\hline & $\mathrm{F}_{\mathrm{D}}=40.16 \mathrm{kmol} / \mathrm{h}$ & $\mathrm{F}_{\mathrm{D}}=39.93 \mathrm{kmol} / \mathrm{h}$ & $\mathrm{F}_{\mathrm{D}}=39.87 \mathrm{kmol} / \mathrm{h}$ \\
\hline & $\mathrm{F}_{\mathrm{S} 1}=9.89 \mathrm{kmol} / \mathrm{h}$ & $\mathrm{F}_{\mathrm{S} 1}=9.96 \mathrm{kmol} / \mathrm{h}$ & $\mathrm{F}_{\mathrm{S} 1}=9.98 \mathrm{kmol} / \mathrm{h}$ \\
\hline & $\mathrm{F}_{\mathrm{S} 2}=10.00 \mathrm{kmol} / \mathrm{h}$ & $\mathrm{F}_{\mathrm{S} 2}=9.94 \mathrm{kmol} / \mathrm{h}$ & $\mathrm{F}_{\mathrm{S} 2}=9.95 \mathrm{kmol} / \mathrm{h}$ \\
\hline & $\mathrm{F}_{\mathrm{L} 1}=225.39 \mathrm{kmol} / \mathrm{h}$ & $\mathrm{F}_{\mathrm{L} 1}=145.73 \mathrm{kmol} / \mathrm{h}$ & $\mathrm{F}_{\mathrm{L} 1}=240.48 \mathrm{kmol} / \mathrm{h}$ \\
\hline & $\mathrm{F}_{\mathrm{V} 2}=306.02 \mathrm{kmol} / \mathrm{h}$ & $\mathrm{F}_{\mathrm{V} 2}=246.73 \mathrm{kmol} / \mathrm{h}$ & $\mathrm{F}_{\mathrm{V} 2}=258.37 \mathrm{kmol} / \mathrm{h}$ \\
\hline & $\mathrm{N}_{\mathrm{F}}=43$ & $\mathrm{~N}_{\mathrm{F}}=44$ & $\mathrm{~N}_{\mathrm{F}}=62$ \\
\hline & $\mathrm{N}_{\mathrm{P} 0}=24$ & $\mathrm{~N}_{\mathrm{P} 0}=35$ & $\mathrm{~N}_{\mathrm{P} 0}=27$ \\
\hline & $N_{P}=135$ & $\mathrm{~N}_{\mathrm{P}}=95$ & $N_{P}=101$ \\
\hline & $\mathrm{N}_{\mathrm{S} 1}=28$ & $\mathrm{~N}_{\mathrm{S} 1}=59$ & $\mathrm{~N}_{\mathrm{S} 1}=44$ \\
\hline & $\mathrm{N}_{\mathrm{S} 2}=31$ & $\mathrm{~N}_{\mathrm{S} 2}=70$ & $\mathrm{~N}_{\mathrm{S} 2}=63$ \\
\hline & $\mathrm{N}_{\mathrm{T}}=141$ & $\mathrm{~N}_{\mathrm{T}}=119$ & $\mathrm{~N}_{\mathrm{T}}=105$ \\
\hline & $\mathrm{Q}_{\mathrm{T}}=25,999.58 \mathrm{~kW}$ & $\mathrm{Q}_{\mathrm{T}}=24,658.87 \mathrm{~kW}$ & $\mathrm{Q}_{\mathrm{T}}=24,338.40 \mathrm{~kW}$ \\
\hline
\end{tabular}

Table 6. Best scheme identified in the design of complex distillation sequences using stochastic optimization methods.

between different problems and is dependent on the problem dimensionality and difficulty. Our results show that SA is a good alternative and offers comparable or better performance than HS and GA methods for this application. In summary, results of this study show the potential of stochastic global optimization methods for solving global optimization problems involved in the design of distillation processes.

\section{Notation}

This notation corresponds to the optimized parameters for the schemes described in this chapter (see Figures 1 to 3 ). 
$\mathrm{B}=$ bottom stream

$\mathrm{D}=$ distillate stream

$\mathrm{F}_{\mathrm{D}}, \mathrm{F}_{\mathrm{S} 1}, \mathrm{~F}_{\mathrm{S} 2}=$ distillate and side (1 and 2$)$ fluxes.

$\mathrm{F}_{\mathrm{L}}=$ flux liquid

FL1, FL2= liquid interconnection stream

$\mathrm{F}_{\mathrm{V}}=$ flux vapor

FV1, FV2= vapor interconnection stream

$\mathrm{N}_{0 \mathrm{Re}}=$ first reaction tray location

$\mathrm{N}_{\mathrm{F}}, \mathrm{N}_{\mathrm{F} 1}, \mathrm{~N}_{\mathrm{F} 2}=$ feed tray location

$\mathrm{N}_{\mathrm{FL}}=$ stream liquid tray location

$\mathrm{N}_{\mathrm{fRe}}=$ last reaction tray location

$\mathrm{N}_{\mathrm{FV}}=$ stream vapor tray location

$\mathrm{N}_{\mathrm{P}}=$ last prefractioner tray location

$\mathrm{N}_{\mathrm{PO}}=$ first prefractioner tray location

NS1,NS2= sidestream tray location

$\mathrm{N}_{\mathrm{T}}, \mathrm{N}_{\mathrm{T} 1}, \mathrm{~N}_{\mathrm{T} 2}=$ total trays

$\mathrm{P}_{0}=$ dome pressure (first stage)

$\mathrm{R}=$ reflux ratio

$\mathrm{S} 1, \mathrm{~S} 2=$ sides streams

$\mathrm{T}_{\mathrm{F}}=$ feed temperature

\section{References}

Aggarwal, A.; \& Floudas, C.A. (1990), Synthesis of General Distillation Sequencess Nonsharp Separations, Comput. Chem. Eng., 14, 6, 631-653, 0098-1354.

Andrecovich, M.J.; \& Westerberg, A.W. (1985). An MILP Formulation for Heat-Integrated Distillation Sequence Synthesis, AIChE J., 31, 9, 1461-1474, 1547-5905.

Bauer, M.H.; \& Stichlmair, J. (1998). Design and Economic Optimization of Azeotropic Distillation Processes Using Mixed-Integer Nonlinear Programming, Comput. Chem. Eng., 22, 9, 1271-1286, 0098-1354.

Bonilla-Petriciolet, A.; Vazquez-Roman, R.; Iglesias-Silva, G.; \& Hall, K. (2006). Performance of Stochastic Global Optimization in the Calculation of Phase Stability Analyses for Nonreactive and Reactive Mixtures, Ind. Eng. Chem. Res., 45, 13, 4764-4772, 0888-5885.

Costa, A.L.H.; da Silva, F.P.T.; \& Pessoa, F.L.P. (2000). Parameter Estimation of Thermodynamic Models for High-Pressure Systems Employing a Stochastic Method of Global Optimization. Braz. J. Chem. Eng., 17, 3, 349-353, 0104-6632.

Caballero, J.A.; \& Grossmann, I.E. (1999). Aggregated Models for Integrated Distillation Systems, Ind. Eng. Chem. Res, 38, 6, 2330-2344, 0888-5885.

Corana A.; Marchesi M.; Martini C.; \& Ridella S. (1987). Minimizing multimodal functions of continuous variables with the 'Simulated Annealing' Algorithm, ACM Trans. Math. Softw., 13, 3, 262-280, 0098-3500.

Dunnebier, G.; \& Pantelides, C.C. (1999) Optimal Design of Thermally Coupled Distillation Columns, Ind. Eng. Chem. Res., 38, 1, 162-176, 0888-5885.

Geem, Z.W. (2009). Music-inspired harmony search algorithm theory and applications, Springer, ISBN: 978-3-642-00184-0, United Sates.

Geem Z.W.; Kim J. H.; \& Loganathan G.V. (2001). A New Heuristic Optimization Algorithm: Harmony Search, Simulation, 76, 2, 60-68, 0037-5497. 
Goffe, B.; Ferrier, G.; \& Rogers, J. (1994). Global optimization of statistical functions with simulated annealing. J. Econom., 60, 1-2, 65-99, 0304-4076.

Hernández, S.; \& Jiménez, A. (1996) Design of Optimal Thermally-Coupled Distillation Systems Using a Dynamic Model, Chem. Eng. Res. Des., 74, 4, 357-362, 0263-8762.

Holland J. (1975). Adaptation in Natural and Artificial Systems, The University of Michigan Press, Ann Arbor, 978-0262581110.

Kim, J.K.; \& Wanakat, P.C. (2004). Quaternary Distillation Systems with Less than N - 1 Columns, Ind. Eng. Chem. Res., 43,14, 3838-3846,.

Kirkpatrick, S.; Gelatt, C. D. Jr.; \& Vecchi, M. (1983). Optimization by Simulated Annealing, Science, 220, 4598, 671-680, 0036-8075.

Kiss, A.; Pragt, J.J.; \& van Strien, G.J.G. (2009). Reactive Dividing-Wall Columns - How to Get More with Less Resources?, Chem. Eng. Comm., 196, 11, 1366-1374, 0098-6445.

Martínez-Iranzo, M.; Herrero, J.M.; Sanchis, J.; Blasco, X.; \& García-Nieto, S. (2009). Applied Pareto Multi-Objective Optimization by Stochastic Solvers, Eng. Appl. Artif Int., 22, 3, 455-465, 0952-1976.

Metropolis N.; Rosenbluth A.; Rosenbluth M.; Teller A.; \& Teller E. (1953). Equation of State Calculations by Fast Computation Machines, J. Chem. Phys., 21, 6, 1087-1092, 0021-9606.

Papalexandri, K.P.; \& Pistikopoulos, E.N. (1996). Generalized Modular Representation Framework for Process Synthesis, AIChE J., 42, 4, 1010-1032, 1547-5905.

Paules, G.E., IV.; \& Floudas, C.A. (1988). A Mixed-Integer Nonlinear Programming Formulation for the Synthesis of Heat-Integrated Distillation Sequences, Comput. Chem. Eng., 12, 6, 531-546, 0098-1354.

Rangaiah G. (2001). Evaluation of Genetic Algorithms and Simulated Annealing for Phase Equilibrium and Stability Problems, Fluid Phase Eq., 187-188, 1, 83-109, 0378-3812.

Smith, E.M.B.; \& Pantelides, C.C. (1995). Design of Reaction/Separation Networks using Detailed Models, Comput. Chem. Eng, 19, S1, S83-S88, 0098-1354.

Steinigeweg, S.; \& Gmehling, J., (2003). Esterification of a Fatty Acid by Reactive Distillation, Ind. Eng. Chem. Res., 42, 15, 3612-3619, 0888-5885.

Triantafyllou, C.; \& Smith, R. (1992). The Design and Optimization of Fully Thermally Coupled Distillation Columns, Chem. Eng. Res. Des, 70, 2, 118-132, 0263-8762.

Vázquez - Castillo, J.A.; Venegas - Sánchez, J.A.; Segovia - Hernández, J.G.; Hernández Escoto, H.; Hernández, S.; Gutiérrez - Antonio, C.; \& Briones - Ramírez, A. (2009) Design and Optimization, using Genetic Algorithms, of Intensified Distillation Systems for a Class of Quaternary Mixtures, Comput. Chem. Eng., 33, 11, 1841-1850, 0098-1354.

Viswanathan, J.; \& Grossmann, I.E. (1993). Optimal Feed Locations and Number of Trays for Distillation Columns with Multiple Feeds, Ind. Eng. Chem. Res., 32, 11, 2942-2949, 0888-5885.

Viveros-García, T.; Ochoa-Tapia, J.A.; Lobo-Oehmichen, R.; de los Reyes-Heredia, J.A.; \& Pérez-Cisneros, E.S. (2005). Conceptual Design of a Reactive Distillation Process for Ultra-Low Sulfur Diesel Production, Chem. Eng J., 106, 2, 119-131, 1385-8947.

Wei-Zhong, A.; \& Xi-Gang, Y. (2009). A simulated Annealing-Based Approach to the Optimal Synthesis of Heat-Integrated Distillation Sequences, Comput. Chem. Eng., 33, 1, 199-212, 0098-1354.

Yang, X-S. (2008). Nature-Inspired Metaheuristic Algorithms. 71-74, Luniver Press, 978-1905986-10-1, United Kingdom.

Yeomans, H.; \& Grossmann, I.E. (2002). Disjunctive Programming Models for the Optimal Design of Distillation Columns and Separation Sequences, Ind. Eng. Chem. Res., 39, 6, 1637-1648, 0888-5885. 


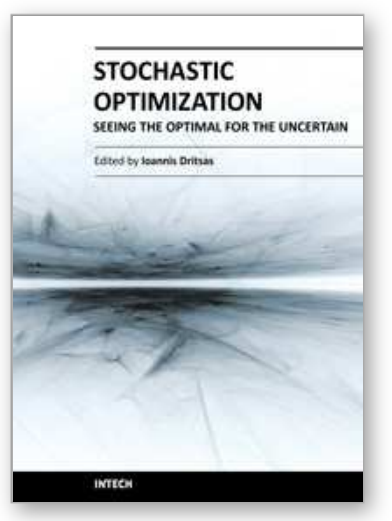

\author{
Stochastic Optimization - Seeing the Optimal for the Uncertain \\ Edited by Dr. loannis Dritsas
}

ISBN 978-953-307-829-8

Hard cover, 476 pages

Publisher InTech

Published online 28, February, 2011

Published in print edition February, 2011

Stochastic Optimization Algorithms have become essential tools in solving a wide range of difficult and critical optimization problems. Such methods are able to find the optimum solution of a problem with uncertain elements or to algorithmically incorporate uncertainty to solve a deterministic problem. They even succeed in â€œfighting uncertainty with uncertaintyâ€. This book discusses theoretical aspects of many such algorithms and covers their application in various scientific fields.

\title{
How to reference
}

In order to correctly reference this scholarly work, feel free to copy and paste the following:

Julián Cabrera-Ruiz, Erick Yair Miranda-Galindo, Juan Gabriel Segovia-Hernández, Salvador Hernández and Adrián Bonilla-Petriciolet (2011). Evaluation of Stochastic Global Optimization Methods in the Design of Complex Distillation Configurations, Stochastic Optimization - Seeing the Optimal for the Uncertain, Dr. Ioannis Dritsas (Ed.), ISBN: 978-953-307-829-8, InTech, Available from: http://www.intechopen.com/books/stochasticoptimization-seeing-the-optimal-for-the-uncertain/evaluation-of-stochastic-global-optimization-methods-in-thedesign-of-complex-distillation-configura

\section{INTECH}

open science | open minds

\section{InTech Europe}

University Campus STeP Ri

Slavka Krautzeka 83/A

51000 Rijeka, Croatia

Phone: +385 (51) 770447

Fax: +385 (51) 686166

www.intechopen.com

\section{InTech China}

Unit 405, Office Block, Hotel Equatorial Shanghai

No.65, Yan An Road (West), Shanghai, 200040, China

中国上海市延安西路65号上海国际贵都大饭店办公楼 405 单元

Phone: $+86-21-62489820$

Fax: $+86-21-62489821$ 
(C) 2011 The Author(s). Licensee IntechOpen. This chapter is distributed under the terms of the Creative Commons Attribution-NonCommercialShareAlike-3.0 License, which permits use, distribution and reproduction for non-commercial purposes, provided the original is properly cited and derivative works building on this content are distributed under the same license. 